\title{
Case Report \\ Successful Intravascular Ultrasound-Guided Transradial Coronary Intervention with a 4Fr Guiding Catheter
}

\author{
Yasuhiro Nakano ${ }^{1}$ and Kenji Sadamatsu ${ }^{2}$ \\ ${ }^{1}$ Department of Cardiovascular Medicine, Saga-Ken Medical Centre KOSEIKAN, Saga, Japan \\ ${ }^{2}$ Department of Cardiovascular Medicine, St. Mary's Hospital, Kurume, Japan \\ Correspondence should be addressed to Yasuhiro Nakano; notch14df@gmail.com
}

Received 23 June 2016; Accepted 25 August 2016

Academic Editor: Expedito E. Ribeiro

Copyright (C) 2016 Y. Nakano and K. Sadamatsu. This is an open access article distributed under the Creative Commons Attribution License, which permits unrestricted use, distribution, and reproduction in any medium, provided the original work is properly cited.

\begin{abstract}
Minimizing the catheter size can reduce vascular access complications and contrast dye usage in coronary angiography. The small diameter of the 4Fr guiding catheter has limited the use of several angioplasty devices such as intravascular ultrasound (IVUS) in the past. However, the combination of a novel IVUS catheter and a 0.010 guidewire makes it possible to perform IVUS-guided percutaneous coronary intervention (PCI) with a 4Fr guiding catheter. We herein report the case of a 51-year-old man with silent myocardial ischemia who underwent IVUS-guided transradial PCI with a 4Fr guiding catheter.
\end{abstract}

\section{Introduction}

Minimizing the catheter size can reduce vascular access complications and contrast dye usage in coronary angiography (CAG) [1]. Intravascular ultrasound- (IVUS-) guided percutaneous coronary intervention (PCI) is associated with significantly lower rates of adverse clinical events compared with angiography-guided PCI [2]. Although the small diameter of a 4 Fr guiding catheter has several critical limitations in the use of angioplasty devices such as IVUS, the combination of a novel IVUS catheter and a 0.010 guidewire may make it possible to perform IVUS-guided PCI with a $4 \mathrm{Fr}$ guiding catheter.

\section{Case Presentation}

A 51-year-old man was admitted to our hospital for acute inferior ST-elevation myocardial infarction 1 month previously, and emergent coronary angiography revealed in-stent restenosis in the distal right coronary artery and severe stenosis of the proximal portion of the second diagonal branch (D2). In-stent restenosis was the culprit lesion and was treated with a drug-coated balloon. One month later, the patient was readmitted to our hospital for elective PCI to the D2 lesion (Figure 1). A 4Fr BL3.5 guiding catheter (KIWAMI Heartrail,
Terumo, Tokyo, Japan) was used to engage the left coronary artery and a 0.010 inch guidewire (Decillion HS, Asahi Intecc, Aichi, Japan) was advanced across stenosis into the distal D2. An IVUS catheter (OptiCross ${ }^{\circledR}$, Boston Scientific, Natick, MA) was passed smoothly in the 4 Fr guiding catheter and the D2 lesion. IVUS images demonstrated that the stenotic lesion was an eccentric fibrous plaque with superficial calcium. After predilation of the lesion with a $2.5 \times 15 \mathrm{~mm}$ scoring balloon (Scoreflex, OrbusNeich, Hong Kong, China), a 3.0 $\times 16 \mathrm{~mm}$ everolimus-eluting stent (Promus Premier, Boston Scientific, Natick, MA) was deployed successfully in the D2 lesion. IVUS images revealed incomplete apposition of the stent struts in the proximal edge (Figure 2); therefore, postdilation of the stent proximal edge was performed using a $3.5 \times 8 \mathrm{~mm}$ noncompliant balloon (Powered Lacrosse 2, Goodman, Aichi, Japan) at a maximum of $16 \mathrm{~atm}$. The final IVUS findings revealed that the apposition of the stent strut was improved (Figure 3), and final angiography showed good results (Figure 4).

\section{Discussion}

TRI can reduce vascular access complications and contrast dye usage in coronary angiography [3]. However, radial artery 


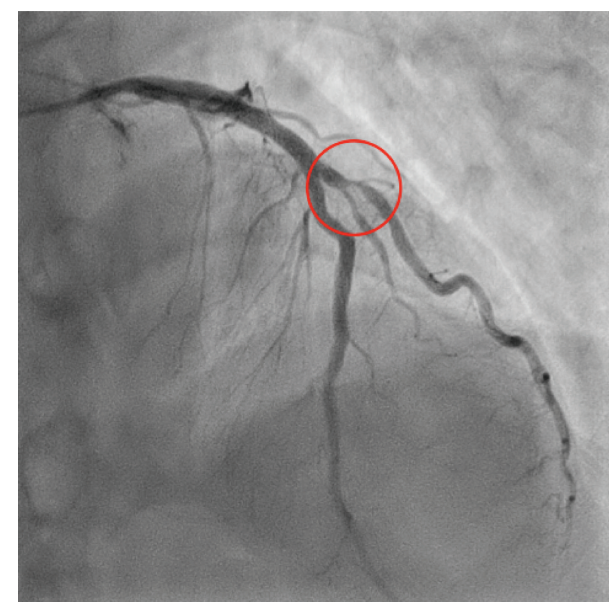

FIGURE 1: Anterior-posterior cranial view showed the significant stenosis of the proximal portion of the second diagonal branch before percutaneous coronary intervention.

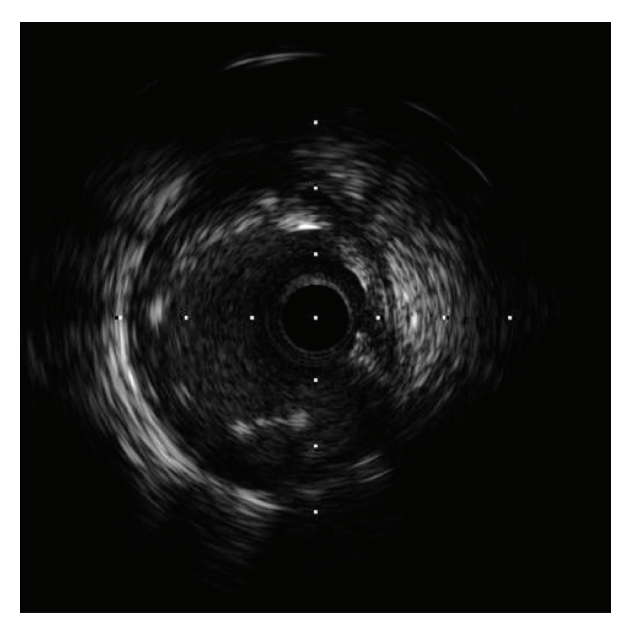

FIGURE 2: Intravascular ultrasound imaging revealed incomplete apposition of the stent struts in the proximal edge.

diameters can vary widely from 1.5 to $4 \mathrm{~mm}$ [4], and a largesized catheter for patients with small radial arteries may cause radial artery occlusion [5]. Thus, the small profile of the catheter, especially $<6$ Fr catheters, referred to as slender PCI, has a favorable impact on vascular access complications [6].

A 4Fr guiding catheter has been developed to facilitate TRI [7]. However, a 4Fr guiding catheter does not allow successful passage of an IVUS catheter because the inner diameter of 4 Fr guiding catheters is limited to 0.050 inches. Recently, a novel IVUS catheter (OptiCross) with a thinner profile has become available. The shaft diameter of the IVUS catheter is 0.0394 inches, and the exit port diameter is 0.0413 inches; thus, the IVUS catheter enables us to use a 4Fr guiding catheter in combination with a 0.010 guidewire (Figure 5). Slender TRI with the 4Fr guiding catheter is less invasive, and moreover, IVUS guidance can be achieved safely and reliably for patients with coronary artery disease. Additionally, we can apply this method to the 4-in-5 mother-child technique for

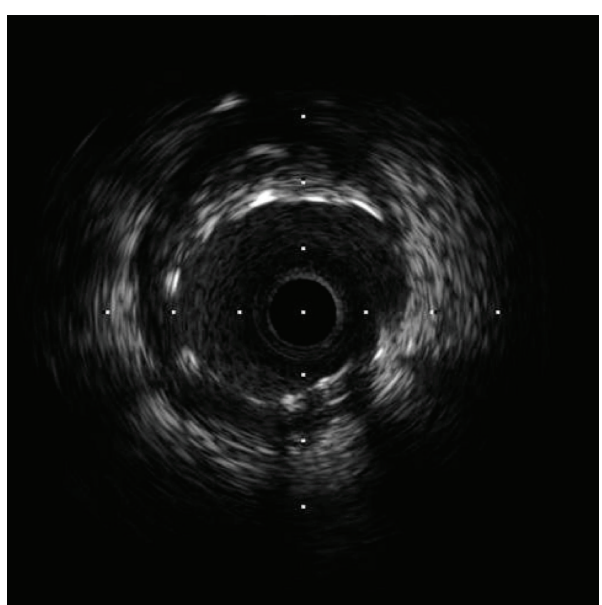

FIGURE 3: Repeat intravascular ultrasound imaging revealed improved apposition of the stent strut.

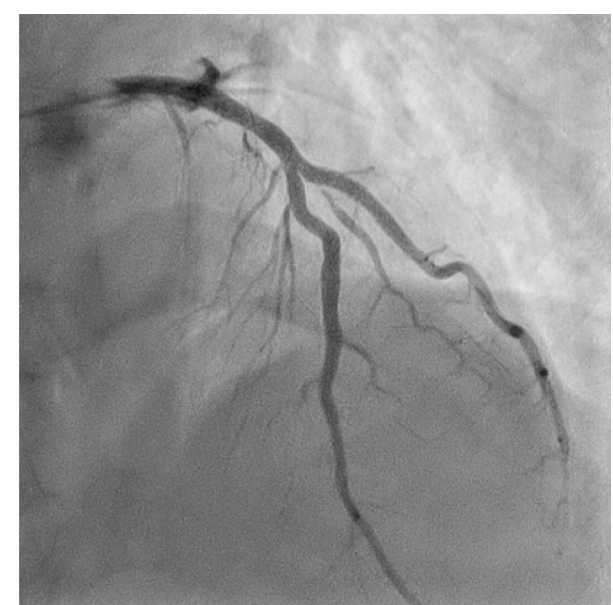

FIGURE 4: Anterior-posterior cranial view showed the widely dilated proximal portion of the second diagonal branch after percutaneous coronary intervention.

treatment of complex coronary lesions [8]. Slender PCI with a 5 Fr guiding catheter is becoming widespread in use; however, one of the critical disadvantages of 5Fr guiding catheters is insufficient backup; thus, it is difficult to use the technique for some complex lesions. The $4 \mathrm{Fr}$ double-coaxial technique (mother-child technique) is one of the solutions to overcome the problem of backup, and the method in this report further supports the use of IVUS in addition to the 4-in-5 motherchild technique for slender PCI in the treatment of complex coronary lesions.

There are several limitations associated with this method. First, the only currently available IVUS catheter for this method is OptiCross due to the limitation of the catheter diameter. Other IVUS catheters are too large to pass through the inner lumen of the 4Fr guiding catheter. Second, a 0.010 guidewire has decreased torque and support; however, the contemporary types of this wire have similar operability to conventional 0.014 guidewires. Third, this method does 


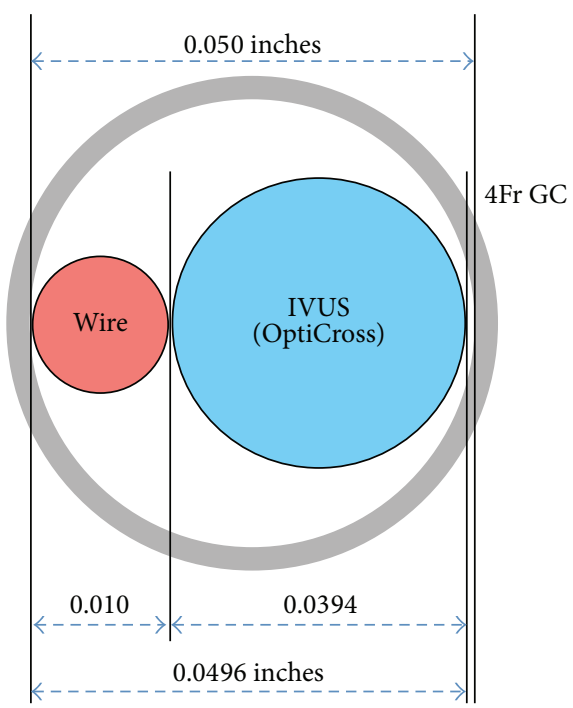

FIGURE 5: A schematic overview showed the respective diameter of $4 \mathrm{Fr}$ guiding catheter, 0.010 guidewire, and intravascular ultrasound catheter.

not allow the IVUS marking technique, which is a way to obtain the optimal angiographic view for stent deployment and appropriate making of the exact position of interest by using IVUS transducer. At present, this method is limited to the selected case. Fourth, the novel introducer sheath of the 5Fr Glidesheath Slender (Terumo, Tokyo, Japan) may be an alternative method to 4Fr PCI. The sheath has the same inner lumen size as that of a conventional $5 \mathrm{Fr}$ sheath, combined with an outer diameter similar to that of a conventional 4Fr sheath [9]. However, the Glidesheath Slender is not available in some countries and more costly compared with conventional introducer sheaths.

\section{Conclusion}

The combination of a novel IVUS catheter and a 0.010 guidewire makes it possible to perform IVUS-guided PCI with a $4 \mathrm{Fr}$ guiding catheter. This method enables less invasive and safer TRI for patients with coronary artery disease.

\section{Competing Interests}

The authors declare no competing interests.

\section{Authors' Contributions}

Yasuhiro Nakano did the cardiac catheterization and intervention and Kenji Sadamatsu also participated in the treatment of this patient.

\section{Acknowledgments}

The authors appreciate the support and collaboration of our catheterization laboratory staff and the member of the Slender Club Japan, and also acknowledge Dr. Fuminobu
Yoshimachi (Associate Professor, Tokai University School of Medicine) and Koji Sugawara (ME, Aomori Prefectural Central Hospital) for their helpful suggestions.

\section{References}

[1] J. B. Dahm, D. Vogelgesang, A. Hummel, A. Staudt, H. Völzke, and S. B. Felix, "A randomized trial of 5 vs. 6 French transradial percutaneous coronary interventions," Catheterization and Cardiovascular Interventions, vol. 57, no. 2, pp. 172-176, 2002.

[2] J. S. Jang, Y. J. Song, W. Kang et al., "Intravascular ultrasoundguided implantation of drug-eluting stents to improve outcome: a meta-analysis," JACC: Cardiovascular Interventions, vol. 7, no. 3, pp. 233-243, 2014.

[3] P. Agostoni, G. G. L. Biondi-Zoccai, M. L. De Benedictis et al., "Radial versus femoral approach for percutaneous coronary diagnostic and interventional procedures: systematic overview and meta-analysis of randomized trials," Journal of the American College of Cardiology, vol. 44, no. 2, pp. 349-356, 2004.

[4] S. Saito, H. Ikei, G. Hosokawa, and S. Tanaka, "Influence of the ratio between radial artery inner diameter and sheath outer diameter on radial artery flow after transradial coronary intervention," Catheterization and Cardiovascular Interventions, vol. 46, no. 2, pp. 173-178, 1999.

[5] M. Rashid, C. S. Kwok, S. Pancholy et al., "Radial artery occlusion after transradial interventions: a systematic review and meta-analysis," Journal of the American Heart Association, vol. 5, no. 1, Article ID e002686, 2016.

[6] F. Kiemeneij, F. Yoshimachi, T. Matsukage et al., "Focus on maximal miniaturisation of transradial coronary access materials and techniques by the Slender Club Japan and Europe: an overview and classification," EuroIntervention, vol. 10, no. 10, pp. 1178-1186, 2015.

[7] S. Takeshita, T. Shiono, A. Takagi, T. Ito, and S. Saito, "Percutaneous coronary intervention using a novel 4-French coronary accessor," Catheterization and Cardiovascular Interventions, vol. 72, no. 2, pp. 222-227, 2008.

[8] K. Tobita, S. Takeshita, and S. Saito, "The 4-in-5 motherchild technique: $5 \mathrm{Fr}$ transradial coronary intervention for complex lesions using a 4 Fr child catheter," Journal of Invasive Cardiology, vol. 25, no. 8, pp. 406-408, 2013.

[9] F. Yoshimachi, F. Kiemeneij, M. Masutani, T. Matsukage, A. Takahashi, and Y. Ikari, "Safety and feasibility of the new 5 Fr Glidesheath Slender," Cardiovascular Intervention and Therapeutics, vol. 31, no. 1, pp. 38-41, 2016. 


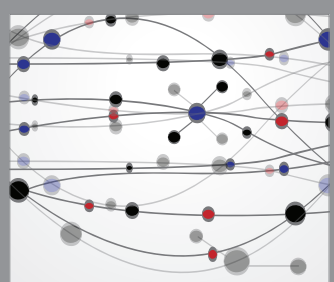

The Scientific World Journal
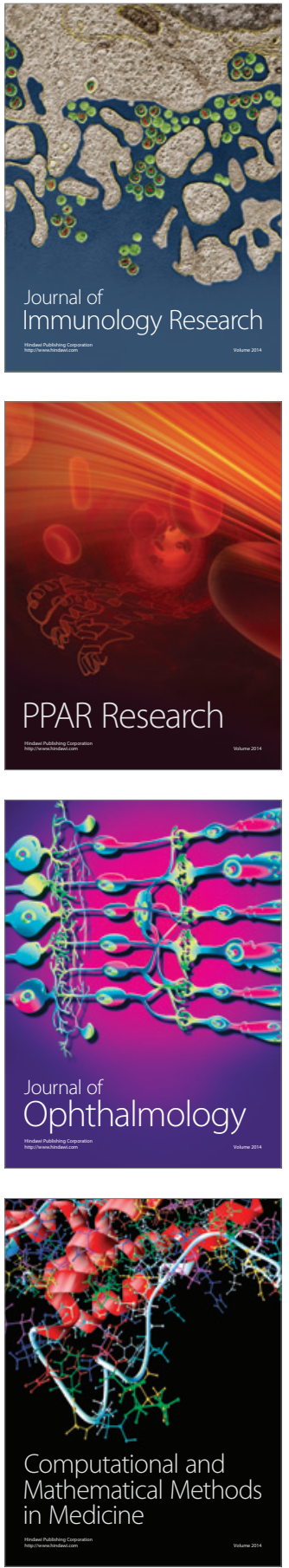

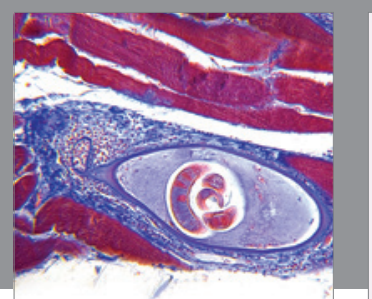

Gastroenterology Research and Practice

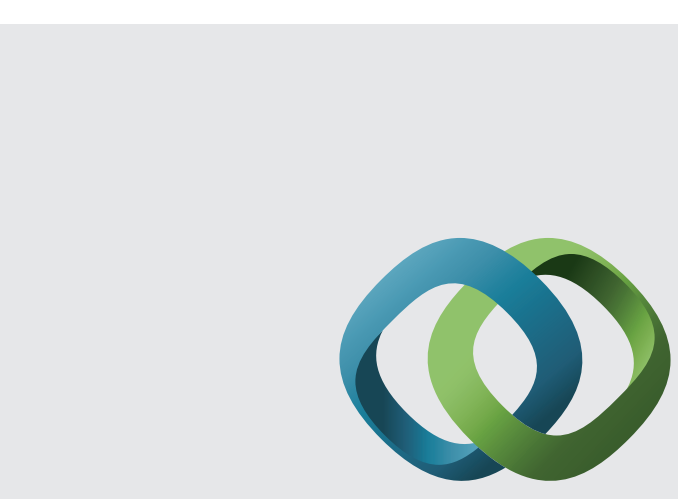

\section{Hindawi}

Submit your manuscripts at

http://www.hindawi.com
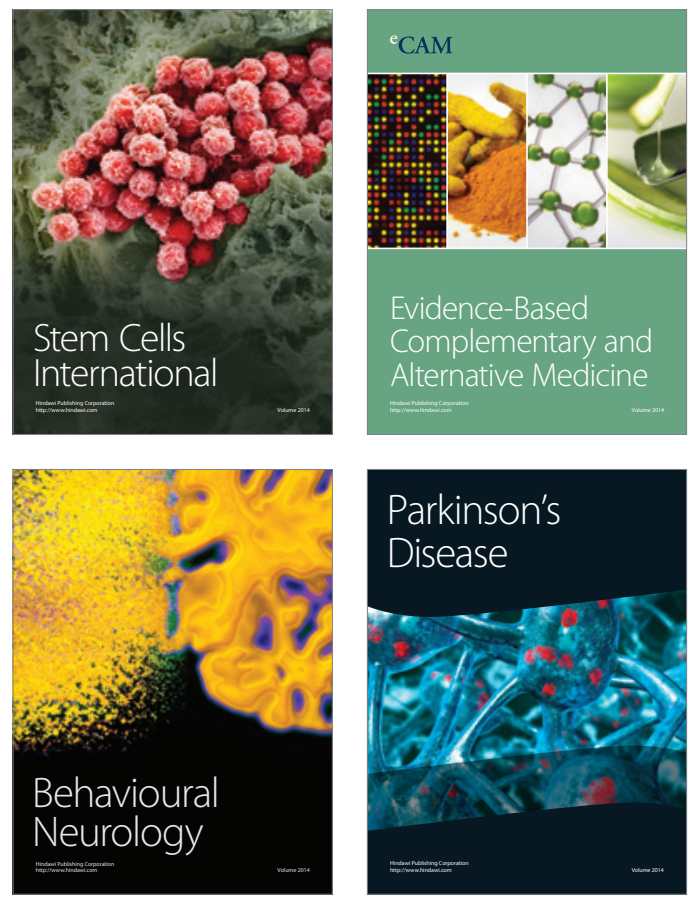
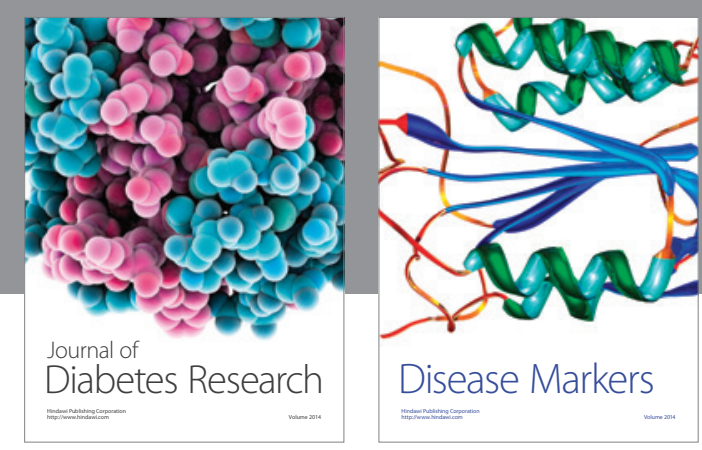

Disease Markers
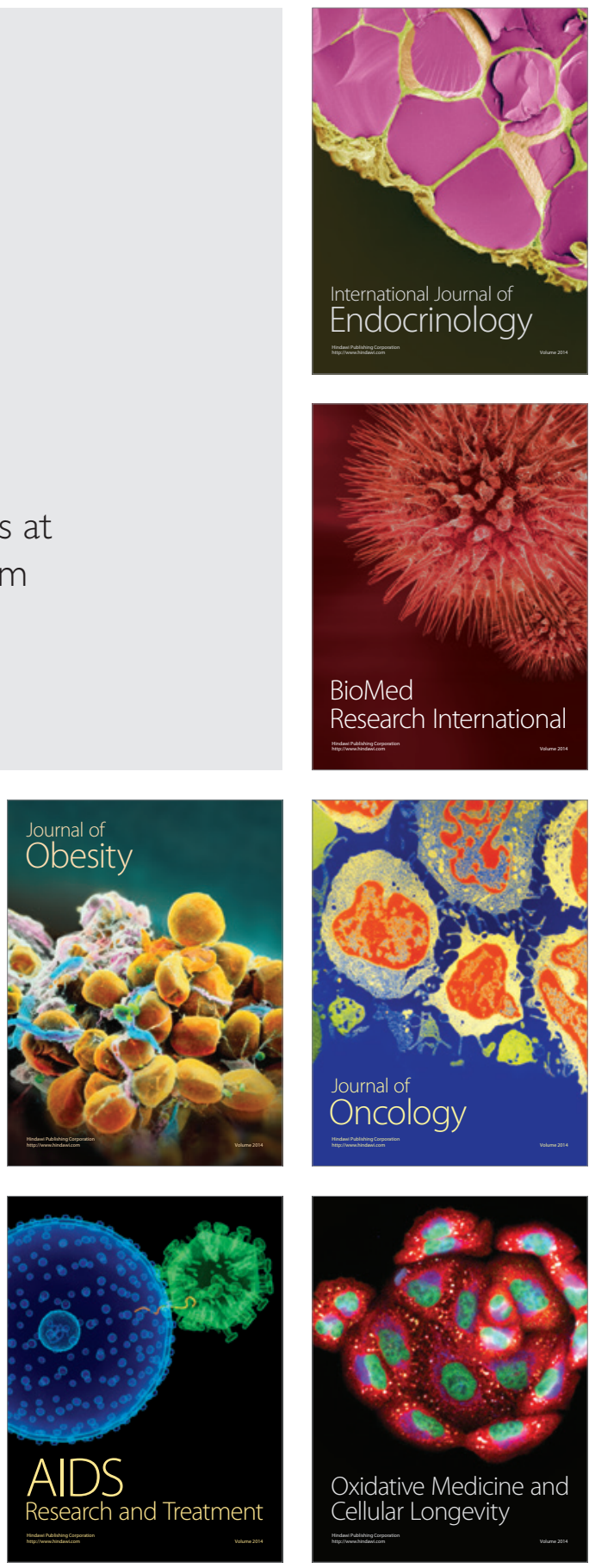